ORIGINAL ARTICLE

\title{
A comparison of the sports safety policies and practices of community sports clubs during training and competition in northern Sydney, Australia
}

\author{
A Donaldson, R Forero, C F Finch, T Hill
}

Br J Sports Med 2004;38:60-63. doi: 10.1136/bjsm.2002.003806

See end of article for authors' affiliations

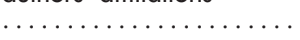

Correspondence to: Mr Donaldson, Northern Sydney Health, Manly Hospital, PO Box 465, Manly, NSW, Australia 2095; adonalds@ doh.health.nsw.gov.au

Accepted 14 January 2003

\begin{abstract}
Objectives: To compare the safety policies and practices reported to be adopted during training and competition by community sports clubs in northern Sydney, Australia.

Methods: This cross sectional study involved face to face interviews, using an 81 item extensively validated questionnaire, with representatives of 163 community netball, rugby league, rugby union, and soccer clubs (response rate 85\%). The study was undertaken during the winter sports season of 2000. Two separate 14 item scales were developed to analyse the level of safety policy adoption and safety practice implementation during training and competition. The statistical analysis comprised descriptive and inferential analysis stratified by sport.

Results: The reliability of the scales was good: Cronbach's $\alpha=0.70$ (competition scale) to 0.81 (training scale). Significant differences were found between the safety scores for training and competition for all clubs (mean difference 11.2; 95\% confidence interval (CI) 10.0 to 12.5) and for each of the four sports: netball (mean difference 14.9; $95 \% \mathrm{Cl} 12.6$ to 17.2); rugby league (mean difference $10.3 ; 95 \% \mathrm{Cl} 7.1$ to 13.6); rugby union (mean difference 9.4; $95 \% \mathrm{Cl} 7.1$ to 11.7 ); and soccer (mean difference $8.4 ; 95 \% \mathrm{Cl}$ 6.5 to 10.3).

Conclusions: The differences in the mean competition and training safety scores were significant for all sports. This indicates that safety policies were less often adopted and practices less often implemented during training than during competition. As injuries do occur at training, and sports participants often spend considerably more time training than competing, sporting bodies should consider whether the safety policies and practices adopted and implemented at training are adequate.
\end{abstract}

S ports injuries are an important public health issue and a key reason for non-participation in physical activity internationally and in Australia. ${ }^{1-7}$ Sports injuries are a significant cost burden for injured participants and the broader community. ${ }^{28}$ One in 17 Australians experience some form of sports related injury every year, and the costs of those injuries have been estimated at one billion Australian dollars a year. ${ }^{2}$ It has been estimated that $70 \%$ of the participants in popular, winter, community level sports in Australia sustain one or more injuries over a two season period. $^{5}$

Several sports injury countermeasures have been described and recommended in the Australian National Sports Safety Framework, including the application of risk management concepts to sports safety. ${ }^{6}$ Manuals and guidelines have been produced to assist sporting organisations to adopt a risk management approach to sports injury prevention. ${ }^{9}$ However, little is known about the extent to which community sports clubs adopt safety policies or implement safety practices. ${ }^{11} 12$

Injuries occur during both competition/matches and training/practice. However, many studies do not report injury risk during training. Between 46\% (elite soccer) and $99 \%$ (elite rugby union) of injuries may occur during matches/ competition and between 1\% (elite rugby union) and 39\% (various competition levels of soccer) may occur during training, depending on the sport, the standard of competition, and the definition of injury used in the study. ${ }^{13-15}$

The rate ratio for injuries in competition versus training has been reported to be as high as 8.3 for club rugby union players in New Zealand ${ }^{16}$ and as low as 1.3 for elite outdoor soccer players in Finland. ${ }^{17}$ No information is available in the literature about the rate ratio for injuries in competition versus training for netball players.

The purpose of this paper is to compare the reported safety policies and practices of four community sporting codes in Australia during training and competition. This is the first time such a study has been reported, and it provides an opportunity to consider the safety policies and practices adopted and implemented during training and competition in the context of the risk of injury in each setting.

\section{METHODS}

Representative samples of community sports clubs participating in netball $(n=59)$, rugby league $(n=20)$, rugby union $(n=35)$, and soccer $(n=49)$ were included in this study. A representative, usually a president or secretary, from each club completed an 81 item questionnaire developed specifically for use with community sporting organisations. ${ }^{11}$ The study was conducted during the 2000 winter sports season.

The questionnaire was based on the National Sports Safety Framework $^{6}$ and a previously used questionnaire. ${ }^{12}$ Questionnaires were completed during a face to face interview. Validity and reliability of the questionnaire, including interrater reliability, test-retest reliability, content validity, and face validity, were confirmed using several methods in a pilot study. ${ }^{11}$

Items in the questionnaire explored whether clubs had adopted specific policies (attendance of qualified first aid personnel; inspection of playing surfaces; wearing or use of protective equipment) and the frequency with which clubs implemented specific safety practices (availability of first aid equipment; attendance of qualified first aid and cardiopul- 
monary resuscitation personnel; access to a telephone; access for emergency vehicles; inspection of playing surfaces; checking of fixtures and fittings; availability of drinking fluids and encouragement to drink at regular intervals; and warming up and cooling down) at training and competition.

Two separate 14 item scales were created to generate a safety score for training and competition for each club. Scale scores were based on two points for having a written policy, one point for having an unwritten policy, one point for implementing a safety practice sometimes $(25 \%)$, two points for implementing a safety practice half the time $(50 \%)$, three points for implementing a safety practice most of the time $(75 \%)$, and four points for implementing a safety practice all the time (100\%). Each scale had a maximum possible score of 50, and a higher score indicates greater attention to safety policies and practices. The interim covariance matrix and Cronbach's $\alpha$ were used to measure the internal consistency of the scales. ${ }^{18}$ This is important because this type of reliability analysis estimates the consistency of different questions intended to measure the same construct. ${ }^{18}$

Statistical analyses included descriptive statistics and $t$ tests for paired samples. Statistical analyses were conducted in Stata version $6 .{ }^{19}$ The differences between mean safety scores at training and competition were calculated by subtracting the mean training safety score from the mean competition safety score for each sport. To determine if these differences were significantly different from zero, 95\% confidence intervals (CI) were calculated.

All subjects gave written informed consent to participate in the study. Ethical approval for the research was obtained from the human research ethics committees of Manly Hospital and Community Health Services, Hornsby, Ryde and Macquarie Hospitals, and Deakin University. Questionnaires were coded to ensure that the identity of individual respondents and the clubs they represented remained confidential.

\section{RESULTS}

A total of 163 respondents, representing $85 \%$ of the community sports clubs in the four codes located within the geographical boundaries for the study, were included in the sample. The response rate varied by sport: rugby union, $78 \%$; rugby league, $80 \%$; netball, $86 \%$; soccer, $92 \%$.

The mean safety score across all clubs $(\mathrm{n}=163)$ for training was 27.8 (range $0-47$ ) and for competition was 39.0 (range 20-50). Cronbach's $\alpha$ was 0.81 for the training scale and 0.70 for the competition scale. For applied studies involving comparisons between groups, most researchers agree that reliability scores above 0.70 are quite acceptable. ${ }^{18}{ }^{19}$ The difference between the mean competition safety score and the mean training safety score across all clubs was $11.2(95 \%$ CI 10.0 to 12.5$)$, indicating that this was significantly different from zero.

Table 1 gives the mean competition and training safety scores for each item on the two scales for each sport and for all clubs. It also gives the total mean competition and training safety scores for each sport and for all clubs. The 59 netball clubs had a mean competition safety score of 41.4 (95\% CI 40.2 to 42.6 ) and a mean training safety score of 26.5 (95\% CI 23.8 to 29.2 ). The 20 rugby league clubs had a mean competition safety score of 42.6 (95\% CI 40.0 to 45.2$)$ and a mean training safety score of 32.3 (95\% CI 28.4 to 36.2 ). The 35 rugby union clubs had a mean competition safety score of 40.2 (95\% CI 38.5 to 41.9 ) and a mean training safety score of 30.8 (95\% CI 28.3 to 33.3 ). The 49 soccer clubs had a mean competition safety score of 34.0 (95\% CI 32.5 to 35.5$)$ and a mean training safety score of 25.6 (95\% CI 23.1 to 27.9 ).

Figure 1 shows significant differences between the mean competition safety scores and the mean training safety scores for each sport. Netball clubs had a difference of 14.9 between the mean competition safety score and the mean training safety score; rugby league clubs had a difference of 10.3, rugby union clubs had a difference of 9.4 , and soccer clubs had a difference of 8.4 .

\section{DISCUSSION}

In contrast with other epidemiological studies which have focused on the proportion and incidence rates of sports injuries sustained in competition and training, this study has compared the safety policies adopted and practices implemented by community sports clubs in these two settings. There is a clear significant difference in the attention given to safety between training and competition. The community sports clubs involved in the four sporting codes included all adopted safety policies and implemented safety practices less often at training than during competitions.

There are a number of reasons why safety receives less attention at training. For instance, the community sports clubs included in this study have probably had less experience of injuries at training, as injuries are less common in this setting. ${ }^{2}{ }^{13-17}$ 20-26 However, the reported proportion of injuries sustained during training and the relative rates of injury at training compared with competition vary widely. ${ }^{2}{ }^{13-}$ ${ }_{17}^{20-26}$ In some sports, including soccer, ${ }^{20}$ the risk of injury is three or four times lower during training than during competition. However, in other sports, such as volleyball, martial arts, and club gymnastics, the injury incidence rates during training are higher than during competitions. ${ }^{26}$ Notwithstanding these variations, injuries do occur during training, and sports bodies should not assume a negligible risk of injury during such activities.

It should be noted that sports participants usually spend anywhere from two to five times as much time training for their sport as they do competing. ${ }^{5} 1315162127$ Therefore, if the injury incidence rate at competition is three times the injury incidence rate at training, as it has been reported to be in soccer, ${ }^{20}$ and participants train three times as often as they take part in competitions, then the relative risk of injury at training is similar to the relative risk of injury during competition in any given time period-for example, a playing career, season, or week.

The activities undertaken at training are generally different from those undertaken during competition, both in nature and intensity. The objective of training is often to develop fitness, skills, and game strategies, at less than full pace, with little or no opposition and limited body contact. Conversely, competition is usually conducted at full pace, with opposition and body contact allowed within the rules of the game. This is particularly relevant to rugby union, rugby league, and soccer where most injuries are sustained during physical contact. ${ }^{14-16212226}$

Another reason why community clubs give less attention to safety at training than at matches may be that the international, national, and regional governing bodies for most sports have mandatory safety policies for governing body sanctioned competitions. It is less common for governing bodies to have safety policies related to training. In this study for example, the mean scores for the items on safety policies at competition (usually the responsibility of governing bodies) were at least twice the score for the corresponding item at training (the responsibility of individual clubs) for all four sports.

It should also be noted that regional associations, either directly or through a proxy such as an umpire or referee, often implement safety practices during competitions, while individual clubs are generally responsible for safety practices at training. For example, netball competitions in Australia are often organised at a central venue, and the relevant regional 
Table 1 Mean safety scores for individual scale items for each sport and for all clubs

\begin{tabular}{|c|c|c|c|c|c|c|c|c|c|c|}
\hline & \multicolumn{2}{|c|}{ Netball $(n=59)$} & \multicolumn{2}{|c|}{$\begin{array}{l}\text { Rugby league } \\
(n=20)\end{array}$} & \multicolumn{2}{|c|}{ Rugby union ( $n=35$ ) } & \multicolumn{2}{|c|}{ Soccer $(n=49)$} & \multicolumn{2}{|c|}{ All clubs $(n=163)$} \\
\hline & Comp & Train & Comp & Train & Comp & Train & Comp & Train & Comp & Train \\
\hline \multicolumn{11}{|l|}{$\begin{array}{l}\text { Policy items (max score per } \\
\text { item }=2 \text { ) }\end{array}$} \\
\hline $\begin{array}{l}\text { Attendance of qualified first } \\
\text { aid providers }\end{array}$ & 1.7 & 0.1 & 1.8 & 0.5 & 0.8 & 0.2 & 0.3 & 0.1 & 1.1 & 0.2 \\
\hline $\begin{array}{l}\text { Safety inspection of playing } \\
\text { surface before use }\end{array}$ & 1.4 & 0.5 & 1.2 & 0.6 & 1.1 & 0.6 & 1.5 & 0.5 & 1.3 & 0.5 \\
\hline $\begin{array}{l}\text { Wearing or using } \\
\text { protective equipment }\end{array}$ & 0.5 & 0.2 & 0.9 & 0.2 & 1.3 & 0.6 & 2.0 & 0.9 & 1.2 & 0.5 \\
\hline \multicolumn{11}{|c|}{ Practice items (max score per item $=4$ ) } \\
\hline $\begin{array}{l}\text { Attendance of qualified first } \\
\text { aid providers }\end{array}$ & 3.8 & 1.1 & 3.5 & 2.2 & 2.6 & 1.5 & 1.2 & 0.8 & 2.7 & 1.2 \\
\hline $\begin{array}{l}\text { Attendance of qualified } \\
\text { CPR providers }\end{array}$ & 3.6 & 1.1 & 3.4 & 2.1 & 2.6 & 1.5 & 0.9 & 0.6 & 2.5 & 1.2 \\
\hline $\begin{array}{l}\text { Availability of first aid } \\
\text { equipment }\end{array}$ & 3.9 & 2.3 & 3.9 & 2.8 & 3.6 & 3.1 & 3.4 & 2.4 & 3.7 & 2.6 \\
\hline Access to a telephone & 4.0 & 3.1 & 4.0 & 3.9 & 4.0 & 3.9 & 3.8 & 3.5 & 3.9 & 3.4 \\
\hline $\begin{array}{l}\text { Clear, unblocked access for } \\
\text { emergency vehicles }\end{array}$ & 4.0 & 2.9 & 3.9 & 3.4 & 3.5 & 3.1 & 3.5 & 3.2 & 3.7 & 3.1 \\
\hline $\begin{array}{l}\text { Safety inspection of playing } \\
\text { surface before use }\end{array}$ & 3.5 & 2.4 & 3.2 & 2.6 & 3.5 & 2.3 & 3.3 & 1.8 & 3.4 & 2.2 \\
\hline $\begin{array}{l}\text { Safety inspection of fixtures } \\
\text { and fittings }\end{array}$ & 2.7 & 1.3 & 4.0 & 1.5 & 4.0 & 2.2 & 3.2 & 2.5 & 3.3 & 1.8 \\
\hline $\begin{array}{l}\text { Availability of drinking } \\
\text { fluid }\end{array}$ & 3.8 & 3.2 & 4.0 & 3.8 & 4.0 & 3.6 & 3.7 & 2.9 & 3.8 & 3.3 \\
\hline $\begin{array}{l}\text { Encouraged to drink fluids } \\
\text { regularly }\end{array}$ & 3.6 & 3.3 & 3.6 & 3.4 & 3.6 & 2.8 & 2.8 & 2.3 & 3.4 & 2.9 \\
\hline Warming up & 3.4 & 3.3 & 3.5 & 3.3 & 3.9 & 3.7 & 3.1 & 2.8 & 3.4 & 3.2 \\
\hline Cooling down & 1.5 & 1.7 & 2.1 & 2.4 & 1.7 & 1.8 & 1.4 & 1.4 & 1.6 & 1.7 \\
\hline Mean total safety score & 41.4 & 26.5 & 42.6 & 32.3 & 40.2 & 30.8 & 34.0 & 25.6 & 39.0 & 27.8 \\
\hline
\end{tabular}

association ensures that a qualified first aid provider is in attendance, that courts are inspected for hazards before they are used, and that emergency vehicle access is kept clear during competitions. In this study, the mean safety score for the attendance of qualified first aid providers at competition among netball clubs (the responsibility of the regional association) was 3.8 compared with 1.1 for the corresponding item at training (responsibility of individual clubs).

In the case of soccer, the referee usually checks that all players are wearing shin protectors and appropriate footwear, and inspects the playing surface and fixtures (goals, corner flags, etc) before the start of a competition. However, referees do not attend club training sessions, and it is unlikely that such safety practices are as comprehensively implemented at training.

Community sports clubs in Australia rely heavily on volunteers to implement safety procedures. It is likely that clubs would find it more difficult to recruit volunteers to

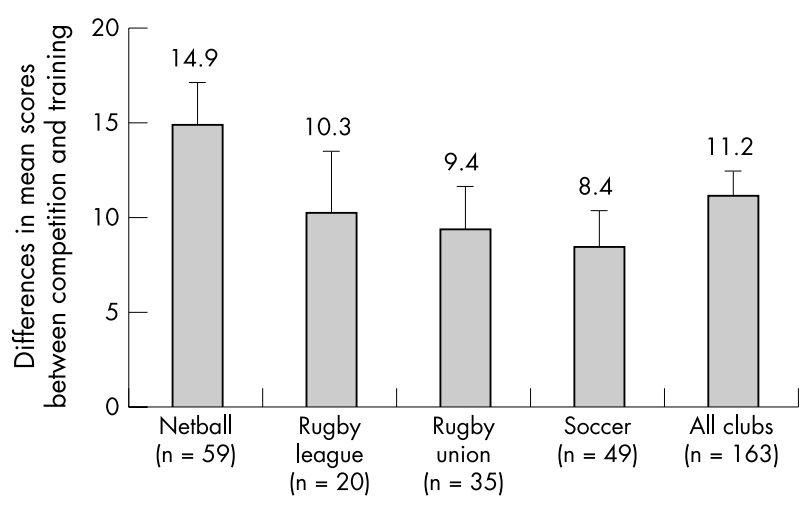

Figure 1 Difference in mean safety scores between competition and training by sport (with $95 \%$ confidence intervals). attend training than to attend matches. It is also likely that safety equipment, such as first aid equipment and protective equipment (goal post padding, etc), is less accessible at training. For example, the first aid kit may be kept and maintained by the first aid provider, who only attends matches.

There are a number of limitations to be considered when interpreting the findings of this study. The sample for the survey was drawn from a limited geographical region and a small number of sports. Any generalisation to the broader sporting community cannot be made without considering the possible differences-social, demographic, economic, geographic, organisational, etc-between the sample population and the groups to which these results are generalised. Nonetheless, there is no reason to believe that the clubs included in this study are very different from other community sporting clubs in Australia.

The findings of this study are based on self reporting by representatives of community sports clubs about the sports safety policies and practices at their club. Therefore there is some potential for reporting bias-because of respondents' interpretations of the questions or desire to report the situation in their club in a certain way-and recall biasbecause of inaccuracies of recall. Furthermore, some club representatives were reporting on policies that were developed and implemented at the association level, and their knowledge of the nature of such policies may have been limited. Only one person represented each club that participated in the study. Therefore the information gathered about each club may be limited by that particular person's knowledge. The club president or secretary was the preferred representative, as the pilot study for this research indicated that this would maximise the potential for obtaining useful information. ${ }^{11}$

The Cronbach's $\alpha$ coefficients for the scales reported in this paper indicate good internal consistency (reliability). 
Correlation coefficients are used to estimate the degree of equivalence between answers. ${ }^{18} 19$ The lower coefficient for the competition scale suggests that this summary scale is not as good as the training summary scale. In general, the $\alpha$ coefficients were sufficiently high for exploratory research such as that reported in this paper. ${ }^{18} 19$

The most important finding of this study is that there is a significant difference in the reported safety policies adopted and practices implemented between training and competition in popular, community level, winter sports clubs. It remains to be ascertained why such a difference occurs. What is now required is some debate about the practical significance of such a difference, with serious consideration given to the question of whether the differences in safety polices and practices between training and competition are commensurate with the differences in risk of injury in each context. This is particularly relevant given the fact that most sports participants spend considerably more time involved in training than competition. It is also important that the barriers to adopting safety policies and implementing safety practices during training and competition are further explored and practical solutions developed to overcome them.

\section{Authors' affiliations}

A Donaldson, T Hill, Northern Sydney Health, Manly Hospital, Manly, NSW, Australia

R Forero, Simpson Centre for Health Services Research, SWS Clinical School, University of New South Wales, Sydney, Australia C F Finch, NSW Injury Risk Management Research Centre, University of New South Wales, Sydney

\section{REFERENCES}

1 Caine DJ, Caine CG, Lindner KJ, eds. Epidemiology of sports injuries. Champaign IL: Human Kinetics, 1996.

2 Egger G. Sports injuries in Australia: causes, cost and prevention. Health Promotion Journal of Australia 1991;1:28-33.

3 Finch C, Valuri G, Ozanne-Smith J. Sports and active recreation injuries in Australia: evidence from emergency department presentations. Br J Sports Med 1998;32:220-5

4 Jago D, Finch C. A survey of sporting and recreational injuries presenting to a general practice. Aust Fam Physician 1998;27:389-95.

5 Finch $C$, daCosta A, Stevenson $M$, et al. Sports injury experiences from the Western Australian sports injury cohort study. Aust N Z J Public Health 2002;26:462-7.
6 Australian Sports Commission. SportSafe Australia; a national sports safety framework. Canberra: Australian Sports Commission, 1997.

7 Finch C, Owen N. Injury prevention and promoting physical activity: what is the nexus? J Sci Med Sport 2001;4:77-87.

8 Avery JG, Harper P, Ackroyd S. Do we pay too dearly for our sport and leisure activities? An investigation into fatalities as a result of sporting and leisure activities in England and Wales 1982-1988. The Society of Public Health 1990;104:417-23.

9 Coalition of Americans to Protect Sports. Sports injury risk management and the keys to safety. North Palm Beach, FL: Coalition of Americans to Protect Sports, 1990

10 Australian Sports Commission. How to become a smartplay club: guidelines to assist clubs develop and implement a sport safety plan. Canberra: Australian Sports Injury Prevention Taskforce, 1998.

11 Donaldson A, Hill T, Finch C, et al. The development of a tool to audit the safety policies and practices of community sports clubs. J Sci Med Sport 2003;6:226-30

12 Finch C, Hennessy M. The safety practices of sporting clubs/centres in the city of Hume. J Sci Med Sport 2000;3:9-16.

13 Engstrom B, Johansson C, Tornkvist H. Soccer injuries among elite female players. Am J Sports Med 1991;19:372-5.

14 Seward H, Orchard J, Hazard H, et al. Football injuries in Australia at the elite level. Med J Aust 1993;159:298-301.

15 Nielsen $\mathbf{A B}$, Yde J. Epidemiology and traumatology of injuries in soccer. Am J Sports Med 1989; 17:803-7.

16 Bird YN, Waller AE, Marshall SW, et al. The New Zealand rugby injury and performance project. V. Epidemiology of a season of rugby injury. Br J Sports Med 1998;32:319-25.

17 Luthje P, Nurmi I, Kataja M, et al. Epidemiology and traumatology of injuries in elite soccer: a prospective study in Finland. Scand J Med Sci Sport 1996:6:180-5.

18 Aday LA. Designing and conducting health surveys, 2nd ed. San Francisco: Jossey Bass Publishers, 1996.

19 Stata-Corp. Stata statistical software: release 6.0. TX: Stata Corporation, 1999.

20 Inklaar H. Soccer injuries: incidence and severity. Sports Med 1994; 18:55-73.

21 Stephenson S, Gissane C, Jennings D. Injury in rugby league: a four year prospective survey. Br J Sports Med 1996;30:331-4.

22 Lee AJ, Garraway WM. Epidemiological comparison of injuries in school and senior club rugby. Br J Sports Med 1996;30:213-17.

23 Poulsen TD, Freund KG, Madsen F, et al. Injuries in high-skilled and lowskilled soccer: a prospective study. Br J Sports Med 1991;25:151-3.

24 Engstrom B, Forssblad $M$, Johansson C, et al. Does a major knee injury definitely sideline an elite soccer player? Am J Sports Med 1990;18:101-5.

25 Yde J, Nielsen AB. Sports injuries in adolescents' ball games: soccer, handball and basketball. Br J Sports Med 1990;24:51-4.

26 Backx FJ, Beijer HJM, Bol E, et al. Injuries in high-risk persons and high-risk sports: a lonitudinal study of 1818 school children. Am J Sports Med 1991; 19:124-30.

27 Peterson L, Junge A, Chomiak J, et al. Incidence of football injuries and complaints in different age groups and skill-level groups. Am J Sports Med 2000;28(suppl 5):S51-7. 